\title{
Hyperbaric Oxygen Therapy: Mechanism of Action and its Application in Periodontics: A Review
}

\author{
Harshita Gupta
}

\begin{abstract}
Hyperbaric oxygen (HBO) therapy is widely used in a number of areas of medical practice. HBO increases local oxygen distribution, especially at the base of the periodontal pocket, which inhibits the growth of anaerobic bacteria and allows the ischemic tissues to receive an adequate intake of oxygen sufficient for a rapid recovery of cell metabolism, which may help to treat many periodontal diseases and also may act as a stimulator of osseointegration which would help during implant placement. The aim of this review article is to collect the information regarding the effects of HBO on periodontal diseases and dental implants. In conclusion, this review has shown that HBO may represent a useful aid, especially in combination with scaling and root planning (SRP), as far as nonsurgical periodontal therapy is concerned.

Keywords: Hyperbaric oxygen therapy, Implants, Periodontal diseases.

International Journal of Oral Implantology and Clinical Research (2018): 10.5005/jp-journals-10012-1180
\end{abstract}

\section{INTRODUCTION}

Periodontal diseases are caused primarily by pathogenic bacteria. The presence of putative periodontal pathogens in the gingival crevice is not sufficient to initiate the inflammation process. Elevation of the relative proportions of these bacteria plays a crucial role in causing tissue and bone damage. ${ }^{1}$

Nowadays, various novel therapeutic approaches are tried as an alternative to conventional therapy or in combination with conventional therapy to reduce the load of periodontopathic pathogens. One of the effective therapeutic measures can be the use of hyperbaric oxygen, $n\left(\mathrm{HBO}_{2}\right)^{2}$

Although the application of compressed gas in medicine had its origin centuries ago, the use of hyperbaric therapy dates back nearly 350 years. The first hyperbaric chamber was created in 1662; today, studies continue to improve and find more uses for hyperbaric oxygen (HBO) therapy. ${ }^{3}$

Hyperbaric literally translates to increased (hyper) pressure (baric). At the sea level, a person is being exposed to normal atmospheric pressure or $1 \mathrm{~atm}$ and breathes approximately $21 \%$ oxygen. In a hyperbaric chamber, this is increased to $100 \%$ oxygen and 1.5-3x normal atmospheric pressure. This allows the blood to carry more oxygen and deliver 15-25 times more oxygen to the tissues and organs of the body. Oxygen has natural healing properties, and increasing the amount that is circulating throughout the body promotes faster and more efficient healing for a wide variety of diseases and ailments. It also provides numerous health benefits. $^{2,4}$

\section{Mechanism of Action}

Therapeutic effects of $\mathrm{HBO}$ can be attributed to its mechanical or hyperoxygenation effects: ${ }^{5-31}$

\section{Hyperoxygenation}

The effect of oxygen-hemoglobin reaction on the transportation of $\mathrm{CO}_{2}$, known as "Haldane" effect, results from the fact that a combination of oxygen with hemoglobin causes it to become a stronger acid. This displaces $\mathrm{CO}_{2}$ from the blood in two ways: first,
Department of Periodontics, Sharda University, Greater Noida, Uttar Pradesh, India

Corresponding Author: Harshita Gupta, Department of Periodontics, Sharda University, Greater Noida, Uttar Pradesh, India, Phone: +91 9910368352, e-mail: gupta_harshita28@yahoo.com

How to cite this article: Gupta H. Hyperbaric Oxygen Therapy: Mechanism of Action and its Application in Periodontics: A Review. Int J Oral Implantol Clin Res 2018;9(1-3):11-16.

Source of support: Nil

Conflict of interest: None

when there is more acid, hemoglobin has less tendency to combine with $\mathrm{CO}_{2}$ to form carbhemoglobin. Much of the $\mathrm{CO}_{2}$ present in this form in the blood is, thus, displaced and, second, the increased acidity of the hemoglobin causes it to release an excess of $\mathrm{H}^{+}$ions, and these, in turn, bind with bicarbonate ions to form carbonic acid which then dissociates into water and $\mathrm{CO}_{2}$, which is released from the blood into the alveoli.

\section{Bubble Size Reduction}

High air pressure decreases the volume of gas bubbles in the blood 2-3 times that of normal air pressure. High oxygen (100\%) intake saturates the blood plasma with oxygen. It is the primary mechanism at work in the management of decompression sickness and arterial gas embolism.

\section{Vasoconstriction}

Elevated levels of oxygen cause vasoconstriction that leads to a reduced blood flow without significantly affecting tissue oxygenation. $\mathrm{HBO}$ is used to control compartment pressures in crush injuries and to treat thermal burns.

\section{Fibroblast Proliferation/Collagen Synthesis}

Oxygen is essential to make and properly organize collagen. Organized collagen is bundled into fibers (like strands in rope), which are interwoven and can be stretched in multiple directions without tearing (the collagen fibers are woven similar to fabric). 
Oxygen is required for the hydroxylation of proline and lysine in procollagen, several posttranslational steps in collagen synthesis (enzymes prolyl hydroxylase, lysyl hydroxylase, and lysyl oxidase), formation of cross-linked triple-helices, and cross-linking by lysyl hydroxylase. Higher oxygen concentrations increase the amount of collagen deposition and tensile strength. It has been shown that increasing oxygen enhances collagen synthesis and tensile strength in both animal and human subjects and can increase the level of collagen organization.

\section{Neovascularization/Angiogenesis}

The creation of new blood vessels, angiogenesis, is essential to the growth and survival of the repaired tissue. Oxygen levels directly affect the rate and the quality of new blood vessel growth. Sufficient oxygen levels are required for correct collagen synthesis (posttranslational hydroxylation), without which the new capillary tubes assemble poorly and remain fragile. Supplemental oxygen accelerates blood vessel growth.

\section{Bactericidal/Bacteriostatic Effect}

$\mathrm{HBO}$ therapy exerts both direct and indirect effects against bacteria. Direct bactericidal and bacteriostatic effects occur through the generation of oxygen-free radicals. This free radical oxidizes proteins and membrane lipids, damages DNA, and inhibits metabolic functions essential for the growth of organisms.

An indirect effect of $\mathrm{HBO}_{2}$ in bacterial killing is through improving leukocytes function and is regarded as being more significant than the direct bactericidal and bacteriostatic effects. Neutrophils require oxygen as a substrate for microbial killing, after phagocytosis occurs. It inhibits the production of alpha-toxin by Welchii and is synergistic with aminoglycosides and quinolones. This is important in the treatment of gas gangrene and necrotizing tissue infection.

\section{Antibiotic Synergism}

$\mathrm{HBO}$ has also been shown to potentiate the effects of certain antibiotics, especially aminoglycosides and sulfonamides.

\section{Increases Cell Metabolism and Energy Production}

Oxygen is required for intracellular processes like biosynthesis, movement, and transport need energy to be functional, as well as for cell survival. Oxygen-dependent enzymes include adenosine triphosphate (ATP) for chemical energy and nicotinamide adenine dinucleotide phosphate (NADPH) oxygenase for respiratory burst (reactive oxygen species (ROS) release). Aerobic glycolysis, $\beta$-oxidation of fatty acids, and the citric acid cycle are tightly attached to the energy acquisition by oxidative phosphorylation and are, therefore, oxygen dependent.

\section{Increases Rate of Cell Proliferation and Reepithelialization}

Epithelial cells "march in" from the sides to close the wound and form a barrier between the wound and the environment-this is the foundation for forming new skin. Fibroblast proliferation and protein production have been reported to be optimal at $160 \mathrm{~mm} \mathrm{Hg}$, i.e., at $\mathrm{pO}_{2}$ levels 2 -fold to 3 -fold higher than those found in healthy tissues, indicating that supplemental oxygen increases the rate of wound repair. Endothelial progenitor cells (EPCs) are essential in wound healing and are triggered by hyperoxia through induction of nitric oxide (NO) with resulting enhancement in ischemic limb perfusion and wound healing.

\section{Promotes Growth Factor Signaling}

ROS are essential for the signaling processes of growth factors and processes such as leukocyte recruitment, cell motility, angiogenesis, and extracellular matrix formation. ROS such as hydrogen peroxide $\left(\mathrm{H}_{2} \mathrm{O}_{2}\right)$ increases vascular endothelial growth factor (VEGF) production in macrophages and keratinocytes. VEGF is a major long-term angiogenic stimulus at the wound site. Platelet-derived growth factor (PDGF) requires ROS in its role to regulate cell growth and division, and angiogenesis.

\section{Increases Antibacterial Activities}

Oxygen is essential for respiratory burst, the production of ROS, used by phagocytes such as neutrophils and macrophages in bactericidal activity, and the removal of necrotic cellular debris. NADPH oxidase, also known as leukocyte oxidase, supports macrophage survival (delay of apoptosis) and enables dead cell cleansing by phagocytosis.

\section{Accelerates Osteoblast Differentiation and Promotes Bone Formation}

Daily exposure to HBOaccelerated the rate of osteoblast differentiation as determined by increased alkaline phosphatase activity and expression of type I collagen and Runx-2 mRNA during the early stages of culture. $\mathrm{HBO}$ also augmented bone nodule formation in hypoxic conditions. HBO had a more pronounced effect on these key markers of osteoblast differentiation than elevated oxygen or pressure alone. $\mathrm{HBO}$ accelerates the rate of osteoblast differentiation.

\section{Rationale Behind HBOt}

According to Kessler et al., ${ }^{32}$ HBOT cannot significantly increase the amount of oxygen bound to hemoglobin molecules but can increase the amount of oxygen dissolved in the plasma.

The positive effects of HBOT stem from the benefit of increasing the tissue oxygen tension and/or pressure within the wound site and include

- Alteration of ischemic effect,

- Reduction of edema,

- Modulation of the production of NO,

- Modification of the effect of growth factors and cytokines,

- Promotion of cellular proliferation,

- Acceleration of collagen deposition,

- Stimulation of capillary budding,

- Accelerated microbial oxidative killing,

- Interference with bacterial proliferation,

- Modulation of the immune system response, and

- Enhancement of oxygen radical scavengers, thereby reducing ischemia-reperfusion injury. ${ }^{33}$

\section{Types of HBO Chambers}

These include the following:

\section{Multiplace Chambers}

These units can accommodate between 2 and 18 or more patients and commonly incorporate a minimum pressure capability of 6.0 atmosphere absolute (ATA).

\section{Advantages}

- Constant patient attendance and evaluation (particularly useful in treating evolving neurological diseases such as decompression sickness and cerebral arterial gas embolism). 
- Multiple patients treated per session.

- Greater working pressure.

\section{Disadvantages}

- Higher capitalization requirements.

- Major space requirements; basement and/or ground floor level limitations.

- Higher operating costs.

\section{Monoplace Chambers}

They were designed for single occupancy and usually constructed of acrylic, having a pressure capability of 3.0 ATA, and compressed with $100 \%$ oxygen. The high flow oxygen requirement is ideally supplied via a hospital's existing liquid oxygen system (Figs 1 and 2).

\section{Advantages}

- Cost-efficient delivery of $\mathrm{HBO}_{2}$.

- No risk of decompression sickness.

- Portable, less space, less equipment, no hood, or mask.

- No risk of iatrogenic decompression sickness in patient or staff.

\section{Disadvantages}

- Relative patient isolation.

- Associated fire hazard.

- Inability to use certain diagnostic and/or therapeutic equipment.

\section{Silicon Trays}

These trays are made up of silicon and oxygen can be supplied to these trays via an anterior valve. The silicon trays are trimmed to the right length and should be adjusted to the individual patient to create a tight fit with the mucous membrane while allowing the oxygen unimpeded access to the gingiva (Fig. 3).

\section{INDICATIONS}

- Air or gas embolism.

- Carbon monoxide poisoning or carbon monoxide poisoning complicated by cyanide poisoning.

- Clostridal myositis and myonecrosis (gas gangrene).

- Crush injury, compartment syndrome, and other acute traumatic ischemia.

- Decompression sickness.

- Enhancement of healing in selected problem wounds: diabetically derived illness, such as diabetic foot, diabetic retinopathy, and diabetic nephropathy.

- Exceptional blood loss (anemia).

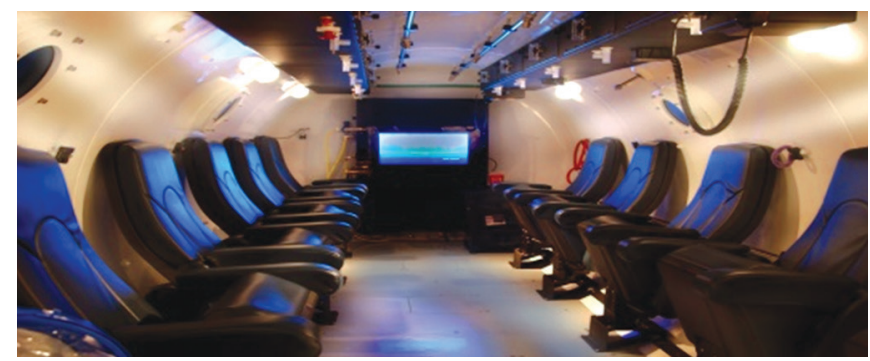

Fig. 1: Multiplace chamber
- Intracranial abscess.

- Necrotizing soft tissue infections (necrotizing fasciitis).

- Osteomyelitis (refractory).

- Delayed radiation injury (soft tissue and bony necrosis).

- Skin grafts and flaps (compromised).

- Thermal burns.

\section{Contraindications}

\section{Absolute Contraindications}

- Untreated pneumothorax

- Bleomycin

- Cisplatin

- Disulfiram

- Doxorubicin

- Sulfamylon

\section{Relative Contraindications}

- Asthma

- Claustrophobia

- Congenital spherocytosis

- Chronic obstructive pulmonary disease (COPD)

- Eustachian tube dysfunction

- High fever

- Pacemakers or epidural pain pump

- Pregnancy

- Seizures

- Upper respiratory infection (URI)

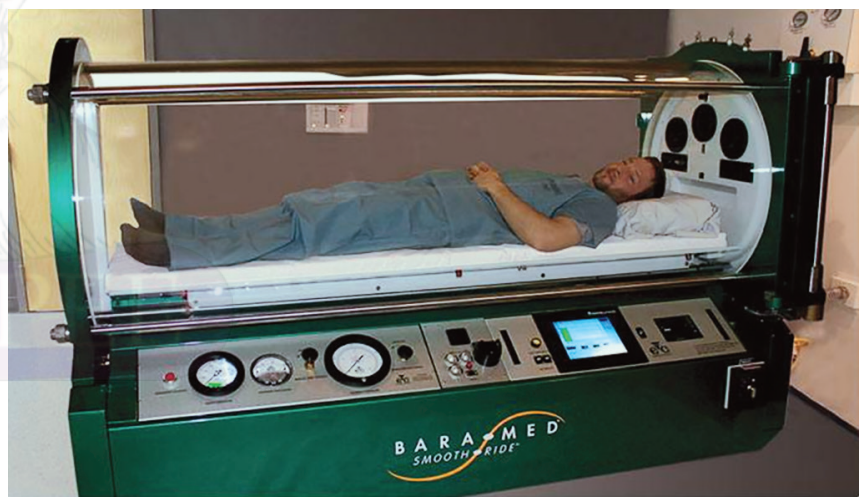

Fig. 2: Monoplace chamber
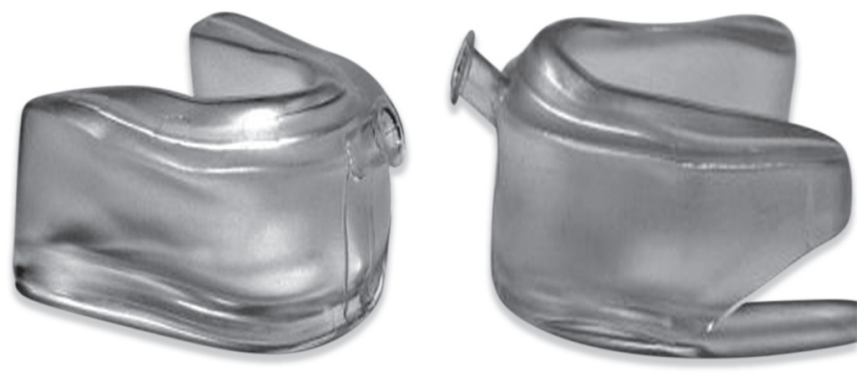

Fig. 3: Silicon trays (maxilla and mandible) 


\section{Effects of HBO Therapy on Periodontal Disease}

\section{Mechanism}

$\mathrm{HBO}$ therapy showed to increase oxygen distribution at the base of the periodontal pocket which is deleterious to periodontal pathogens, particularly to the anaerobic microorganisms. Cultivation of plaque microorganisms from sites of chronic periodontitis reveals high percentages of anaerobic (90\%) bacterial species. ${ }^{34,35} \mathrm{HBO}_{2}$ increases the generation of oxygenfree radicals, which oxidize proteins and membrane lipids, damage deoxyribonucleic acid, and inhibit bacterial metabolic functions. It also facilitates the oxygen-dependent peroxidase system by which leukocytes kill bacteria. $\mathrm{HBO}_{2}$ also improves the oxygen-dependent transport of certain antibiotics across bacterial cell walls. In this way, HBOT results in the inhibition of bacterial growth. ${ }^{36}$

While, on the contrary, HBOT would also allow the ischemic tissues to receive an adequate intake of oxygen sufficient for a rapid recovery of cell metabolism. Oxygen tension in periodontal pockets is very low $\left(\mathrm{O}_{2} 5-27 \mathrm{~mm} \mathrm{Hg}\right)$ when compared with atmospheric $p \mathrm{O}_{2}(155 \mathrm{~mm} \mathrm{Hg})$, the arterial blood $p \mathrm{O}_{2}(95 \mathrm{~mm} \mathrm{Hg})$, and the venous blood $\mathrm{pO}_{2}(20-40 \mathrm{~mm} \mathrm{Hg}){ }^{37,38}$ Fibroblast and leukocyte function are severely compromised when $p \mathrm{O}_{2}$ is $\leq 30 \mathrm{~mm} \mathrm{Hg}$. $\mathrm{HBO}_{2}$ increases collagen formation for capillary growth. $\mathrm{HBO}_{2}$ also promotes fibroblast replication and collagen formation, while the patient is in the hyperbaric chamber. It also increases the bactericidal function of leukocytes. HBOT also improves gingival microcirculation and increases gingival blood flow.

Thus, in periodontal tissues, HBOT showed to have a deleterious effect on periodontal microorganisms as well as beneficial effects on periodontal healing by raising oxygen tension in the pocket.

\section{Evidence}

Guentherman et al. ${ }^{39}$ showed through an experiment that periodontal pathology induced in dogs was treated with hyperoxygenation. Blood oxygen tensions were elevated to at least $1,900 \mathrm{~mm} \mathrm{Hg}$ by means of a HBO chamber for 2 hours twice a day, 2 days a week for 4 weeks. Clinical appearance and loss of alveolar bone were recorded in treated and untreated animals. On the one hand, the animals receiving $\mathrm{HBO}$ had gingival tissues that appeared clinically healthy and were found to have an only modest bone loss at the end of 8 weeks. On the other hand, the control animals often had grossly inflamed gingiva and marked loss of bone at the end of the 8-week period.

Manhold et al. ${ }^{40}$ showed through an experiment that some commercially available oxygenating agents demonstrated shorter healing times when applied on inflamed gingiva.

Hirsch et al. ${ }^{41}$ studied the effect of locally released oxygen on the development of plaque and gingivitis in man and concluded that there was no significant effect of oxygen on plaque formation, crevicular fluid flow, or the number of gingival bleeding sites.

Schlagenhauf et al. ${ }^{42}$ and Issac et al. ${ }^{43}$ used repeated subgingival oxygen irrigations in previously untreated periodontal patients. They concluded that repeated oxygen insufflations resulted in a significant clinical improvement of the periodontal baseline conditions superior to the one found in the control.
Gaggl et al. ${ }^{44}$ applied localized oxygenation in contrast to systemic oxygen therapy, to help treat acute necrotizing periodontal diseases. In both groups of patients, colonization with Prevotella intermedia, Tannerella forsythia, and Treponema denticola was initially positive. None of these microorganisms was completely eradicated in any of the patients in the group without oxygen therapy within the first 10 days.

Signoretto et al. ${ }^{36}$ evaluated the effects of $\mathrm{HBO}_{2}$ on patients suffering from adult chronic periodontitis in comparison with surgical intervention (SRP), as well as the effects of a combination of both therapies on the evolution over time of the microflora of the periodontal pockets and found that the combination of $\mathrm{HBO}_{2}$ and SRP substantially reduced (by up to $99.9 \%$ ) the Gram-negative anaerobe loads of the subgingival microflora. The low values of pathogens persisted for at least 2 months after the therapy. $\mathrm{HBO}_{2}$ or SRP alone produced a temporarily more limited effect on periodontal anaerobes. In addition, molecular detection of the main periodonto-pathogenic bacteria significantly reduced in the number of dental sites, which harbored them.

Nogueira-Filho et al. ${ }^{45}$ evaluated the effect of HBOT as an adjunct to SRP in the treatment of severe cases of periodontitis. They concluded that HBOT had a short-term beneficial effect on pocket reduction and bacterial elimination, and may be considered a potential adjunct therapeutic option to improve the clinical outcomes of scaling in severe cases of chronic periodontitis.

Chen et al. ${ }^{46}$ investigated the effects of $\mathrm{HBO}_{2}$ on aggressive periodontitis (AgP) and subgingival obligate anaerobes in Chinese patients and concluded that $\mathrm{HBO}_{2}$ inhibits the growth of subgingival obligate anaerobes and facultative anaerobes and bacteroides melaninogenicus, thus, promoting healing of peridontium, which will be of help in the treatment of $\mathrm{AgP}$. $\mathrm{HBO}_{2}$ therapy combined with SRP appears to be even better for synergistic treatment of AgP. The effects can last $>2$ years.

Ganesha et al. ${ }^{47}$ evaluated the efficacy of HBOT as an adjunctive therapy for patients suffering from chronic periodontitis, after applying the conventional therapy of scaling and root planing (SRP). Also, the study aimed to investigate the required number of HBOT sessions for treatment. Fifty-four patients aged 30-50 years with chronic periodontitis and $4-6 \mathrm{~mm}$ of pocket depth were divided into three treatment groups: SRP treatment only, SRP with 8 sessions of HBOT, and SRP with 16 sessions of HBOT. As clinical data, pocket depth, clinical attachment level, and bleeding on probing were monitored for a period of up to 1 month. The results showed that HBOT can be beneficial as an adjunctive therapy of chronic periodontitis when combined with SRP and that 8 sessions of HBOT are sufficient for the purpose.

Marx et al. ${ }^{48}$ evaluated 18 bony reconstructions of the mandible or the maxilla using a newly defined and specific $\mathrm{HBO}$ protocol have been reported. Eleven of 12 grafts in irradiated tissue met six rigid criteria for a $91.6 \%$ rate of success. All six grafts into scarred and deficient tissue beds also met the same criteria, for an overall success rate of $94 \%$. The rationale for emphasizing preoperative tissue preparation using $\mathrm{HBO}$ is discussed, as are the mechanisms of action of $\mathrm{HBO}$ on a biochemical, cellular, and tissue level. Neovascularity and neocellularity are demonstrated histologically by human biopsy specimens, and this is suggested as being the reason for the excellent results of reconstruction in irradiated and/or deficient tissue beds. 


\section{HBO AND IMPLANT}

Dental implants offer a way to replace missing teeth. Patients who have undergone radiotherapy or surgery may benefit from reconstruction with implants.

\section{Mechanism}

$\mathrm{HBO}$ has been shown to affect angiogenesis, bone metabolism, and bone turnover. In relation to radiotherapy, $\mathrm{HBO}_{2}$ can, thus, counteract some of the negative effects of irradiation and actually act as a stimulator of osseointegration. The exact mechanisms at the cellular level where $\mathrm{HBO}_{2}$ acts remain obscure. It has been recently shown that $\mathrm{HBO}_{2}$ and basic fibroblast growth factor (bFGF) acts synergistically in the irradiated bone. Factors that could be involved in bone protection by bFGF and $\mathrm{HBO}_{2}$ are bone marrow radioprotection, induction of oxygen radical scavengers, and production of different cytokines.

$\mathrm{HBO}$ and bFGF can also enhance the level of insulin growth factor, which is known to promote proliferation and differentiation of bone. They could also affect bone progenitor cells by promoting DNA synthesis, stimulating enzymes involved in bone formation, or affect membrane receptors. $\mathrm{HBO}_{2}$ has furthermore been shown to affect the interface between the titanium implant and the bone, which could be different from the cellular effect.

Oxygen under hyperbaric conditions could, thus, play a role in osseointegration by affecting bone cell metabolism, implant interface, and capillary network in the implant bed.

\section{Evidence}

Taylor and Worthington ${ }^{49}$ reported that when implants were placed in conjunction with $\mathrm{HBOT}$, healing was more reliable, although still slow. They recommended $\mathrm{HBO}_{2}$ for patients treated with >50 Gy.

Johnsson ${ }^{50}$ investigated the influence of a single $15 \mathrm{~Gy}$ dose of irradiation on the capacity of titanium screws to integrate with the irradiated bone tissue. The biomechanical force necessary to unscrew the titanium implants 8 weeks after placement was $54 \%$ lower for implants in irradiated bone tissue compared to implants in nonirradiated bone tissue. Postirradiation use of HBO treatment at 2.8 ATA ( 2 hours daily treatments for 21 days) increased the biomechanical force necessary to unscrew the titanium implants by $44 \%$ in the irradiated bone and by $22 \%$ in the nonirradiated bone.

Andersson et al. ${ }^{51}$ concluded that the implant treatment for oral rehabilitation can be carried out as a safe and successful procedure in the irradiated patient without adjunctive HBO therapy. Marx and Morales ${ }^{52}$ reported a 5 -years survival in 622 out of 748 osseointegrated implants after $\mathrm{HBO}_{2}$ treatment.

Granström et al. ${ }^{53}$ in a case-controlled study found that about $53.7 \%$ implants failed in the irradiated group compared to $13.5 \%$ in the nonirradiated group and $8.1 \%$ for the irradiated $\mathrm{HBO}_{2}$-treated group. He concluded that the implant insertion in the irradiated bone is associated with a higher failure rate. Adjuvant $\mathrm{HBO}$ treatment can reduce the failures. Johnsson et al. ${ }^{54}$ concluded that irradiation reduces the capacity for osseointegration of titanium implants. HBO treatment may improve bone formation and, especially, has positive effects on bone maturation after irradiation.

Granstrom $^{55}$ and Teoh et al. ${ }^{56}$ concluded that the adjunctive use of $\mathrm{HBO}$ treatment with implant installation is strongly recommended. Brandt and Balanoff ${ }^{57}$ concluded that using an accepted hyperbaric oxygenation protocol when placing and restoring immediate implants in their case report resulted in a successful treatment outcome.

Esposito et al. ${ }^{58}$ and Coulthard et al. ${ }^{59}$ in a systematic review found only one randomized controlled trial (RCT) comparing $\mathrm{HBO}_{2}$ with no $\mathrm{HBO}_{2}$ for implant treatment in irradiated patients and they concluded that HBOT in irradiated patients requiring dental implants may not offer any appreciable clinical benefits. There is a definite need for more RCTs to ascertain the effectiveness of $\mathrm{HBO}_{2}$ in irradiated patients requiring dental implants. Grecchi et al. ${ }^{60}$ in the case of mandible osteonecrosis after a severe peri-implant infection observed that the risk of developing osteonecrosis of the jaw for oral implants is low after HBO therapy. Nyberg et al., ${ }^{61}$ Chambrone et al., ${ }^{62}$ Wadhawan et al., ${ }^{24}$ and Shah et al. ${ }^{63}$ concluded that the HBO can be the effective treatment protocol for the implant treatment in irradiated maxillofacial patients.

\section{Conclusion}

HBO has been successfully used in several medical applications. It has been described as "a therapy in search of diseases."

Several studies have described the beneficial role of HBO in the treatment of various human pathologies either alone or in combination with other therapies. Very few studies have been conducted to analyze the effects of HBO therapy on periodontal disease. Although available evidences are few, HBOT was shown to improve gingival blood flow and microcirculation and inhibit the growth of periodontal pathogens in periodontal pocket when used alone or in combination with conventional periodontal therapy. In future, further research is required to be conducted to prove potential benefits of HBOT.

\section{References}

1. Mahale SA, Kalasva PK, et al. Hyperbaric oxygen therapy in periodontal diseases. J Int Clin Dent Res Organ 2013;5:3-8. DOI: 10.4103/2231-0754.134129.

2. Popat RP, Popat PR. Role of hyperbaric oxygen therapy in the treatment of periodontitis. SRM J Res Dent Sci 2014;5:102-105. DOI: 10.4103/0976-433X.132082.

3. Available http://newlifemedgroup.com/history-of-hyperbaricoxygen-therapy/.

4. Jain N, Deepa D. Applications of hyperbaric oxygen therapy in dentistry: A mini review. J Interdiscip Dent 2014;4:27-32. DOI: 10.4103/2229-5194.135007.

5. Available http://www.centrehyperbare.com/pdfs/hyperbaremechanism-of-action.pdf.

6. Available https://www.ncbi.nlm.nih.gov/pubmed/24984320.

7. Available https://www.ncbi.nlm.nih.gov/pubmed/18019088.

8. Ertracht $\mathrm{O}$, Arieli R, et al. Optimal oxygen pressure and time for reduced bubble formation in the $\mathrm{N}_{2}$-saturated decompressed prawn. J Appl Physiol 2005;98:1309-1313. DOI: 10.1152/japplphysiol.01051.2004.

9. Available https://www.anesth.uiowa.edu/clinicscenters/hyperbaricmedicine/abouthbo/mechanismofaction.

10. Available http://www.scopemed.org/?mno=11098\#abstract.

11. Available http://emedicine.medscape.com/article/1464149overview\#a2.

12. Boerema I, Meyne NG, et al. Life without blood. A study of the influence of high atmospheric pressure and hypothermia on dilution of the blood. J Cardiovascular Surg 1960;1:133-146.

13. Available http://www.hyperbaric.im/page_119780.html.

14. Nylander $G$, Lewis $D$, et al. Reduction of postischemic edema with hyperbaric oxygen. Plast Reconstr Surg 1985;76(4):596-603. DOI: 10.1097/00006534-198510000-00021.

15. Waili NS. Hyperbaric Oxygen in the Treatment of Patients With Cerebral Stroke, Brain Trauma, and Neurologic Disease. Adv Ther 2005;22(6):659-678. DOI: 10.1007/BF02849960.

16. Available http://www.eo2.com/resources/how-oxygen-works.pdf.

17. Siddiqui A, Davidson JD, et al. Ischemic tissue oxygen capacitance after hyperbaric oxygen therapy: a new physiologic concept. Plast Reconstr Surg 1997;99:148-155. DOI: 10.1097/00006534-19970100000023. 
18. Hohn DC, Ponce B, et al. Antimicrobial systems of the surgical wound. I. A comparison of oxidative metabolism and microbicidal capacity of phagocytes from wounds and from peripheral blood. Am J Surg 1977;133:597-600. DOI: 10.1016/0002-9610(77)90018-6.

19. Mirhij NJ, Roberts RJ, et al. Effects of hypoxemia upon aminoglycoside serum pharmacokinetics in animals. Antimicrob Agents Chemother 1978 Sep;14(3):344-347. DOI: 10.1128/AAC.14.3.344.

20. Muhvich KH, Park MK, et al. Hyperoxia and the Antimicrobial Susceptibility of Escherichia coli and Pseudomonas aeruginosa. Antimicrob Agents Chemother 1989;33(9):1526-1530. DOI: 10.1128/ AAC.33.9.1526

21. Yamanel L, Kaldirim U, et al. Ozone Therapy and Hyperbaric Oxygen Treatment in Lung Injury in Septic Rats. Int J Med Sci 2011;8(1):48-55. DOI: $10.7150 /$ ijms.8.48.

22. Smith JL. The pathological effects due to increase of oxygen tension in the air breathed. Ann Chim 1849;19-35.

23. Prabowo S, Nataatmadja M, et al. Hyperbaric Oxygen Treatment in a Diabetic Rat Model Is Associated with a Decrease in Blood Glucose, Regression of Organ Damage and Improvement in Wound Healing. Health 2014;6:1950-1958. DOI: 10.4236/health.2014. 615228.

24. Wadhawan $R$, Reddy $Y$, et al. Hyperbaric oxygen therapy; utility in medical \& dental fields a review. J Sci 2014;4(10):604-614.

25. Gottrup F. Oxygen in wound healing and infection. World J Surg 2004;28:312-315. DOI: 10.1007/s00268-003-7398-5.

26. Tandara AA, Mustoe TA. Oxygen in wound healing-more than a nutrient. World J Surg 2004;28:294-300. DOI: 10.1007/s00268-0037400-2.

27. Sheikh AY, Gibson JJ, et al. Effect of hyperoxia on vascular endothelial growth factor levels in a wound model. Arch Surg 2000;135:1293-1297. DOI: 10.1001/archsurg.135.11.1293.

28. Marx RE. Radiation injury to tissue. In: Kindwall EP. ed. Hyperbaric Medicine Practice, 2nd ed., Flagstaff (AZ): Best Publishing Company; 1999. pp. 665-723.

29. Greenwood TW, Gilchrist AG. Hyperbaric oxygen and wound healing in post-irradiation head and neck surgery. Br J Surg 1973 May;60(5):394-397.

30. Hadia HA, Smerdonb GR, et al. Hyperbaric oxygen therapy accelerates osteoblast differentiation and promotes bone formation. J Dent 2015;43:382-383. DOI: 10.1016/j.jdent.2014.10.006.

31. Svalestad J, Thorsen E, et al. Effect of hyperbaric oxygen treatment on oxygen tension and vascular capacity in irradiated skin and mucosa. Int J Oral Maxillofac Surg 2013;1-6.

32. Kessler $L$, Bilbault $P$, et al. Hyperbaric oxygenation accelerates the healing rate of nonischemic chronic diabetic foot ulcers. Diabetes Care 2003;26:2378-2382. DOI: 10.2337/diacare.26.8.2378.

33. Thackham JA, McElwain DL, et al. The use of hyperbaric oxygen therapy to treat chronic wounds: A review. Wound Rep Reg 2008;16:321-330. DOI: 10.1111/j.1524-475X.2008.00372.x.

34. Gupta V, Vijay S, et al. Hyperbaric Oxygen Therapy. JK-Practitioner 2005;12(1):44-47.

35. Teughels W, Quirynen M, et al. Periodontal microbiology. In: Newman MG, Takei HH, et al. ed. Carranza's Clinical Periodontology, 11th ed., St. Louis, Missouri: Saunders Publication; 2012.

36. Signoretto $C$, Bianchi $F$, et al. Microbiological evaluation of the effects of hyperbaric oxygen on periodontal disease. New Microbiol 2007;30:431-437.

37. Tanaka M, Hanioka T, et al. Association of Oxygen Tension in Human Periodontal Pockets With Gingival Inflammation. J Periodontol 1998;69:1127-1130. DOI: 10.1902/jop.1998.69.10.1127.

38. Mettraux GR, Gusberti FA, et al. Oxygen Tension $\left(\mathrm{pO}_{2}\right)$ in Untreated Human Periodontal Pockets. J Periodontol 1984;55(9):516-521. DOI: 10.1902/jop.1984.55.9.516.

39. Guentherman RH, Bishop JG, et al. The Effect of Increased Blood Oxygen Tensions on Induced Periodontal Disease. J Periodontol 1972;43(4):233-236. DOI: 10.1902/jop.1972.43.4.233.
40. Manhold $\mathrm{JH}$, Weisinger $\mathrm{E}$, et al. Gingival tissue oxygenation: The effect of daily application of four commercial preparations. J Periodontol 1974;45:312-313. DOI: 10.1902/jop.1974.45.5.1.312.

41. Available https://www.ncbi.nlm.nih.gov/pubmed/6941974.

42. Schlagenhauf $U$, Horlacher $V$, et al. Repeated subgingival oxygen irrigations in untreated periodontal patients. J Clin Periodontol 1994;21:48-50.

43. Issac AV, Mathew JJ, et al. Management of Chronic Periodontitis Using Subgingival Irrigation of Ozonized Water: A Clinical and Microbiological Study. J Clin Diagn Res 2015;9(8):ZC29-ZC33. DOI: 10.7860/JCDR/2015/14464.6303.

44. Gaggl AJ, Rainer $\mathrm{H}$, et al. Local oxygen therapy for treating acute necrotizing periodontal disease in smokers. J Periodontol 2006;77: 31-38. DOI: 10.1902/jop.2006.77.1.31.

45. Available https://www.ncbi.nlm.nih.gov/pubmed/20462143.

46. Chen $T L, X u B$, et al. Effects of hyperbaric oxygen on aggressive periodontitis and subgingival anaerobes in Chinese patients. J Indian Soc Periodontol 2012;16:492-497. DOI: 10.4103/0972-124X. 106880.

47. Wandawa G, Mustaqimah DN, et al. Efficacy of Hyperbaric Oxygen Therapy as an Adjunctive Therapy of Chronic Periodontitis. J Int Dent Med Res 2017;10(1):72-75.

48. Available https://www.ncbi.nlm.nih.gov/labs/articles/7045303/.

49. Available https://www.ncbi.nlm.nih.gov/pubmed/8455170.

50. Johnsson K, Hansson A, et al. The Effects of Hyperbaric Oxygenation on Bone-Titanium Implant Interface Strength With and Without Preceding Irradiation. Int J Oral Maxillofac Implants 1993;8:415-419.

51. Andersson G, Andreasson L, et al. Oral Implant Rehabilitation in Irradiated Patients Without Adjunctive Hyperbaric Oxygen. Int J Oral Maxillofac Implants 1998;13:647-654.

52. Available https://www.ncbi.nlm.nih.gov/pubmed/9421676.

53. Available http://www.joms.org/article/S0278-2391(99)90059-9/pdf.

54. Johnsson AA, Sawaii T, et al. A Histomorphometric Study of Bone Reactions to Titanium Implants in Irradiated Bone and the Effect of Hyperbaric Oxygen Treatment. Int J Oral Maxillofac Implants 1999;14:699-706.

54. Granstrom G. Radiotherap, osseointegration and hyperbaric oxygen therapy. Periodontol 2000 2003;33:145-162.

56. Teoh KH, Huryn JM, et al. Implant prosthodontic rehabilitation of the fibula-free flap reconstructed mandibles: a memorial sloan kettering cancer center review of prognostic factors and implant outcomes. Int J Oral Maxillofac Implants 2005;20:738-746.

57. Brandt RL, Balanoff W. Immediate Placement of Implants and Appliance in an Irradiated Patient: A Case Study. Clin Implant Dent Relat Res 2007;9(2):116-119. DOI: 10.1111/j.1708-8208.2007.00037.x.

58. Available http://www.cochrane.org/CD003603/ORAL_interventionsfor-replacing-missing-teeth-hyperbaric-oxygen-therapy-forirradiated-patients-who-require-dental-implants.

59. Coulthard P, Patel $S$, et al. Hyperbaric oxygen therapy for irradiated patients who require dental implants: a Cochrane review of randomised clinical trials. Eur J Oral Implantol 2008;1(2): 105-110.

60. Grecchi F, Zollino I, et al. A case of mandible osteonecrosis after a severe periimplant infection. Dent Res J 2012;9:S233-S236. DOI: 10.4103/1735-3327.109768.

61. Nyberg J, Hertzman S, et al. Osseointegration of implants in irradiated with or without hyperbaric oxygen treatment: an experimental study in rat tibiae. Int J Oral Maxillofac Implants 2013;28:739-746. DOI: 10.11607/jomi.3083.

62. Chambrone L, Mandia J, et al. Dental Implants Installed in Irradiated Jaws: A Systematic Review. J Dent Res 2013;92:119S-130S. DOI: $10.1177 / 0022034513504947$

63. Shah DN, Chauhan CJ, et al. Effectiveness of hyperbaric oxygen therapy in irradiated maxillofacial dental implant patients: a systematic review with meta-analysis. J Indian Prosthodont Soc 2017;17:109-119. DOI: 10.4103/0972-4052.203193. 